\title{
SIMULATIONS OF FLOW CIRCULATIONS AND ATRAZINE CONCENTRATIONS IN A MIDWEST U.S. RESERVOIR
}

\author{
XIANGGUI ZHAO \\ State Key Laboratory for Environmental Geochemistry, Institute of Geochemistry, \\ Chinese Academy of Sciences, Guiyang, Guizhou 550002, China \\ ROY R. GU \\ College of Environmental Science \& Engineering, South China University of Technology, Guangzhou, \\ China and Department of Civil, Construction and Environmental Engineering, Iowa State University \\ Ames, Iowa 50011, USA \\ roygu@iastate.edu \\ CHULING GUO \\ College of Environmental Science \& Engineering, South China University of Technology \\ Guangzhou, Guangdong, China \\ KUI WANG \\ School of Civil Engineering, Guangxi University \\ Nanning, Guangxi, China \\ SHIJIE LI \\ State Key Laboratory for Environmental Geochemistry, Institute of Geochemistry, \\ Chinese Academy of Sciences, Guiyang, Guizhou 550002, China
}

\begin{abstract}
Atrazine is the most commonly used herbicide in the spring for pre-emergent weed control in the corn cropping area in the Midwestern United States. A frequent high level of herbicide concentrations in reservoirs is a great concern for public health and aquatic ecosystems. In this study, a two-dimensional hydrodynamics and toxic contaminant transport model was applied to Saylorville Reservoir, Iowa, USA. The model simulates physical, chemical, and biological processes and predicts unsteady vertical and longitudinal distributions of a toxic chemical. Model results were validated by measured temperatures and atrazine concentrations. Simulated flow velocities, water temperatures, and chemical concentrations demonstrated that the spatial variation of atrazine concentrations was largely affected by seasonal flow circulation patterns in the reservoir. In particular, the simulated fate and transport of atrazine showed the effect of flow circulation on spatial distribution of atrazine during summer months as the river flow formed an underflow within the reservoir and resulted in greater concentrations near the surface of the reservoir. Atrazine concentrations in the reservoir peaked around the end of May and early June. A thorough understanding of the fate and transport of atrazine in the reservoir can assist in developing operation and pollution prevention strategies with respect to timing, amount, and depth of withdrawal. The responses of atrazine transport to various boundary conditions provide useful information in assessing environmental impact of alternative upstream watershed management practices on the quality of reservoir water.
\end{abstract}

Keywords: Hydrodynamics; temperatures; toxic chemicals; velocities; water quality. 


\section{Introduction}

Significant amounts of herbicides are flushed into surface waters from the agricultural fields in the Midwestern U.S. during late spring and early summer storm events ${ }^{1}$. Atrazine [2-chloro-4-ethylamino-6-isopropylamino-1,3,5-triazine] is the most commonly used herbicide in the spring for pre-emergent weed control in the corn cropping area in the Midwestern United States. Approximately 3.4 million $\mathrm{kg}$ of atrazine are applied to the agricultural fields in Iowa annually with a typical application rate of $1.6-3.4 \mathrm{~kg} / \mathrm{ha}^{2}$. Atrazine is the most frequently detected herbicide in 76 Midwestern reservoirs ${ }^{3}$ including Saylorville Reservoir, Iowa (Fig. 1). A long-term residence time of reservoir water containing atrazine is problematic because atrazine having elevated concentrations can persist for much longer periods of time under the regulated flow condition than the natural river condition. A frequent high level of herbicide concentrations in the reservoirs is a great concern for public health and aquatic ecosystems. Previous studies have shown the evidence of chronic and harmful effects of atrazine on human health. Atrazinecontaminated drinking water may contribute to higher risks of breast cancer in women ${ }^{4}$. Because atrazine is not easily removed from drinking water by conventional water treatment processes, tap water concentrations are similar to raw water concentrations unless a high-level treatment process such as carbon filtration is employed ${ }^{5}$. Therefore, information on the occurrences, persistence, and temporal and spatial distributions of atrazine is needed for optimized reservoir operations and adequate water management.

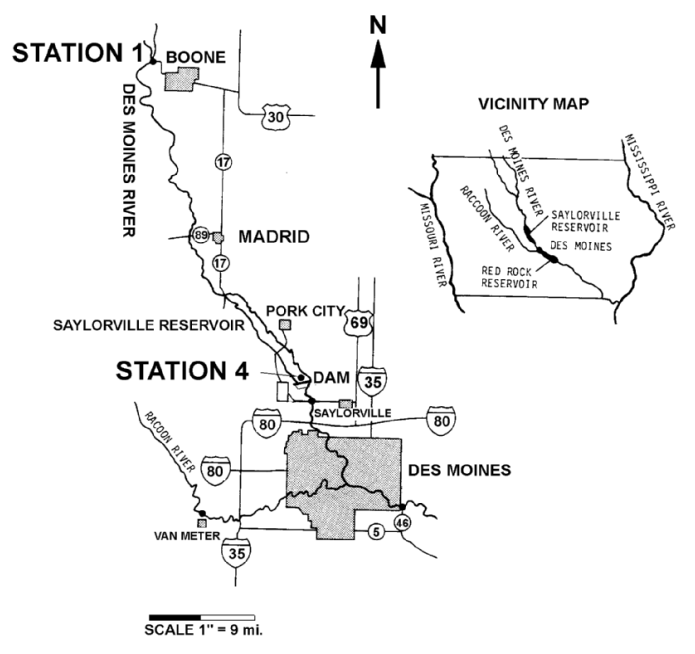

Fig. 1. Saylorville Reservoir and sampling stations.

As the fate of atrazine can be complex in a stratified reservoir and highly influenced by seasonal reservoir circulation patterns, a mathematical model is needed for accurately simulating hydrodynamic processes and chemical reaction kinetics to capture the temporal and spatial distributions of atrazine in the reservoir. A laterally integrated, twodimensional (2D) hydrodynamics and transport model ${ }^{6}$, CE-QUAL-W2, has been widely 
used for modeling temperature and conventional constituents (i.e., dissolved oxygen and nutrient) in many reservoirs ${ }^{7,8}$. However, the model is not capable of modeling the fate of toxic substances. A modeling component for toxic chemicals was then developed and incorporated into CE-QUAL-W2 model by Gu and Chung ${ }^{9}$.

The objective of this study was to validatethe enhanced 2D reservoir modeland to simulate the fate and transport of atrazinein the Midwestern reservoir, Saylorville Reservoir, Iowa. Modeled atrazine concentrations and their temporal and spatial (longitudinal and vertical) distributions in the reservoir were compared with field data and observations. The fate and transport of atrazine were analyzed using the observed and simulated flow velocities, water temperatures, and concentrations. Site-specific and timevariable atrazine transformation rates were used, which are a function of environmental conditions, i.e., sunlight, temperature, and microorganisms. A sensitivity analysis was conducted to identify the potential model error associated with the use of a lumped value of transformation rate (or half-life).

\section{Methodology}

\subsection{Model Description}

The 2D reservoir contaminant model simulates unsteady vertical and longitudinal distributions of toxic chemicals in water column and bed sediments in response to various boundary loads: upstream, tributary, overland runoff, groundwater, and atmospheric ${ }^{9}$. It is a laterally integrated model, which was developed using the finite-difference solution to the equations of horizontal momentum, mass transport, free water surface elevation, hydrostatic pressure, continuity, and the equation of state for density ${ }^{6}$. The state variables include water surface elevation, pressure, density, horizontal and vertical velocities, and chemical concentration. The independent variables are longitudinal distance, vertical flow depth, and time. The transport and fate of atrazine in a reservoir are described by the conservation of mass. The governing equations for total atrazine concentration in the water column $\left(\mathrm{C}_{\mathrm{t}, \mathrm{w}}\right)$ and in bed sediments $\left(\mathrm{C}_{\mathrm{t}, \mathrm{b}}\right)$ were expressed as:

$$
\begin{gathered}
\frac{\partial\left(B C_{t, w}\right)}{B \partial t}+\frac{\partial\left(U B C_{t, w}\right)}{B \partial x}+\frac{\partial\left(W B C_{t, w}\right)}{B \partial z}-\frac{\partial}{B \partial x}\left(B D_{x} \frac{\partial C_{t, w}}{\partial x}\right)-\frac{\partial}{B \partial z}\left(B D_{z} \frac{\partial C_{t, w}}{\partial z}\right) \\
=\frac{K_{f}}{y}\left(f_{d, b} C_{t, b} / \varphi-f_{d, w} C_{t, w}\right)-K_{t} f_{d, w} C_{t, w}+\frac{k_{l}}{z}\left\{\left(C_{a} / H\right)-f_{d, w} C_{t, w}\right\}-\frac{v_{s}}{z} f_{p, w} C_{t, w}+\Phi_{N P S} \\
\frac{\partial\left(B C_{t, b}\right)}{B \partial t}=-\frac{K_{f}}{y}\left(f_{d, b} C_{t, b} / \phi-f_{d, w} C_{t, w}\right)-K_{t} f_{d, b} C_{t, b}+\frac{v_{s}}{z} f_{p, w} C_{t, w},
\end{gathered}
$$

where subscripts $t, d$ and $p$ denote the total, dissolved, and particulate phases of atrazine; subscripts $a, w$ and $b$ denote air, water, and bed; $f_{d}$ and $f_{p}$ are the fractions of dissolved and particulate chemicals to total chemical; $t$ is time; $x$ is longitudinal coordinate; $B$ is width; $U$ and $W$ are longitudinal and vertical velocities; $D x$ and $D z$ are longitudinal and vertical dispersion coefficients; $K_{f}$ is diffusive exchange rate between water column and 
pore water; $\phi$ is bed sediment porosity; $K_{t}$ is the sum of first-order kinetic transformation rates for atrazine photolysis, hydrolysis, and biotransformation; $k_{l}$ is air-water exchange rate resulting from volatilization; $H$ is Henry's law constant; $C_{a}$ is vapor phase concentration; $\Phi_{N P S}$ is nonpoint source (NPS) mass flow rate per unit volume; $v_{s}$ is net settling velocity; $\mathrm{z}$ is depth; and $\mathrm{y}$ is vertical distance from bottom.

The chemical considered is expected to be in dissolved and particulate forms and vary in longitudinal and vertical directions of the water column and the bed sediments. The chemical kinetic reaction rates and model input parameters are determined from field and laboratory experiments, estimation using chemical properties, and from the literature ${ }^{9,10}$. In the model, various degradation processes, such as photolysis, hydrolysis, oxidation, and volatilization were computed, either separately by providing individual kinetic reaction rates or collectively by providing a lumped value of transformation rate or halflife. A time-variable half-life value was specified through the model input. The model uses a net settling velocity as inputs for sediments, which does not explicitly account for particle type, grain size, density, viscosity, and turbulence. The nonpoint source loading can be estimated either by a simple mass balance model or a complicated NPS model.

\subsection{Evaluation methods}

Goodness-of-fit tests selected for evaluating the model performance include absolute mean error (AME), normalized root mean square error (RMSE), and Nash-Sutcliffe efficiency coefficient $(\mathrm{EF})$ :

$$
\begin{gathered}
A M E=\left(\sum_{i=1}^{n}\left|O_{i}-P_{i}\right|\right) / n, \\
R M S E=\left[\sum_{i=1}^{n}\left(P_{i}-O_{i}\right)^{2} / n\right]^{0.5}, \\
E F=\left(\sum_{i=1}^{n}\left(O_{i}-O_{m}\right)^{2}-\sum_{i=1}^{n}\left(P_{i}-O_{i}\right)^{2}\right) / \sum_{i=1}^{n}\left(O_{i}-O_{m}\right)^{2},
\end{gathered}
$$

where $O_{i}$ and $P_{i}$ are the observed and predicted values at each comparison point $i, n$ is the number of observed and predicted values that are being compared, and $O_{m}$ is the mean of the observed values.

AME is the average of the absolute values of differences between observed data and simulated values. RMSE basically specifies the overall difference in the sum of squares normalized to the number of observations. Both AME and RMSE give an indication of the magnitude of the model's prediction uncertainty for a typical data point. RMSE is similar to a standard error of the mean for the model's uncertainty. The desired value is zero for the AME and RMSE, and one for the EF. 


\subsection{Study site and input data}

The Saylorville Reservoir is located on the upper Des Moines River basin, Iowa (Fig. 1). At full flood control pool, i.e., at the elevation of $271.3 \mathrm{~m}$, the reservoir extends $86.9 \mathrm{~km}$ above dam and occupies about $67.6 \mathrm{~km}^{2}$. Upstream drainage area is $15,081 \mathrm{~km}^{2}$. The mean and maximum depths of the reservoir are $4.3 \mathrm{~m}$ and $13.8 \mathrm{~m}$ at the conservation level, respectively. Approximately $79 \%$ of the upstream watershed was cropland, $6 \%$ was permanent pasture, 5\% was forest, and 7\% was urban. Annual precipitation was $797 \mathrm{~mm}$.

Field data were collected weekly or biweekly in 1978 at two sampling stations, denoted as Stations 1 (upstream) and 4 (within the reservoir). These stations are part of 8 sampling stations installed in the Des Moines River basin to monitor the long-term impacts of Saylorville and Red Rock reservoirs on water quality and quantity ${ }^{11,}{ }^{12}$. Station 1 is located near the Boon water plant about $71.8 \mathrm{~km}$ upstream from the Saylorville Dam, and is considered as the upstream boundary of the reservoir at conservation pool. Station 4 is located within the reservoir with an upstream drainage area of $15,081 \mathrm{~km}^{2}$. Water samples were collected from three depths (subsurface, middepth, and bottom) at Station 4.

The time frame of model application was from March 1 to September 30, 1978 because it corresponds to the corn-growing season, and the time when atrazine concentrations exceed the MCL $(3.0 \mu \mathrm{g} / \mathrm{L})$ for drinking water. A variable time-step was computed to maintain numerical stability using an auto-stepping algorithm that was embedded in the model. The average time step was 1088 seconds over the simulation period. The initial conditions for water temperature and atrazine concentration in the reservoir were set at $2^{\circ} \mathrm{C}$ and $0.01 \mu \mathrm{g} / \mathrm{L}$ for all cells, respectively, based on the field measurement data for February 28, 1978.

The flow data at upstream boundary were collected at the upstream gauging station (Station 1). The daily values of precipitation, inflow, outflow, and reservoir water storage during the study period are presented in Fig. 2. The atrazine concentrations, water temperatures, and SS concentrations measured weekly or biweekly at the upstream sampling station were used as the time-variable upstream boundary conditions (Fig. 3).

Meteorological data were obtained from the National Oceanic and Atmospheric Administration station at Des Moines, Iowa, located $20 \mathrm{~km}$ downstream of the reservoir. The daily meteorological data were used to compute solar radiation, equilibrium temperatures, and coefficients of heat exchange, and surface heat exchange.

The nonpoint source (NPS) mass flow rate $\left(\Phi_{N P S}\right)$ collectively included the contributions of these tributaries and the distributed atrazine loading along the main branch of the reservoir. The NPS loading rate in this study was estimated based on the amount of atrazine that was applied within the watershed, the percentage of total atrazine that was delivered to the waterbody, and a weighting factor that represents a seasonal loading pattern of atrazine at the study site. 

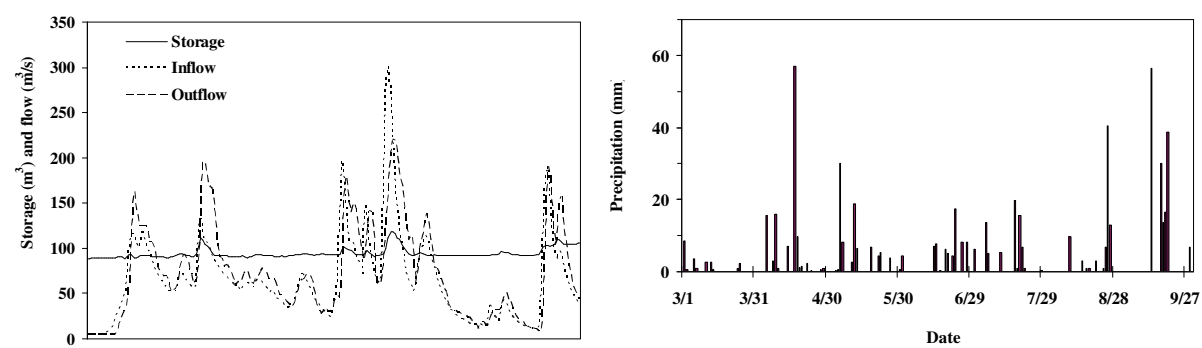

Fig. 2. Daily precipitation, inflow, outflow, and storage of the Saylorville Reservoir during the study period.

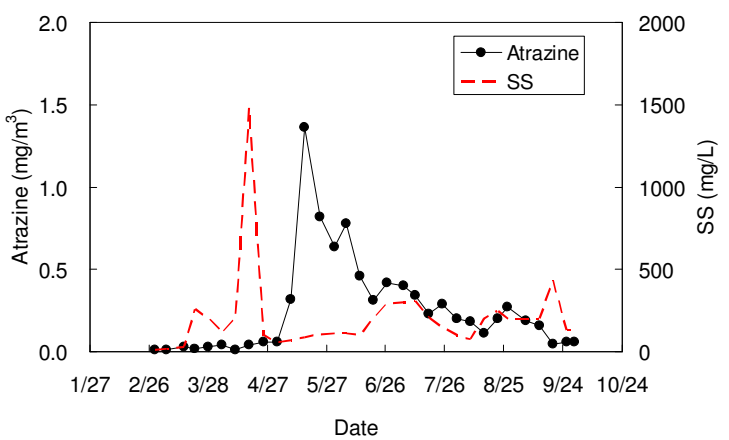

Fig. 3. Atrazine and suspended solid (SS)concentrations measured at inflow boundary of Saylorville Reservoir.

\section{Results and Discussion}

\subsection{Flow fields and water temperatures}

Accurate simulations of water balance, hydrodynamics, and thermal structure over time are important to the prediction of the fate and transport of atrazine in a reservoir. Therefore, simulated water elevations were compared with the observed values to examine and validate the accuracy of water balance computation of the model in Fig. 4. The model results followed the observed water surface variations reasonably well during the entire study period. The AME, RMSE, and EF values between observed and simulated water surface elevations are $0.102 \mathrm{~m}, 0.143 \mathrm{~m}$, and 0.721 , indicating that water balance was met during the simulation.

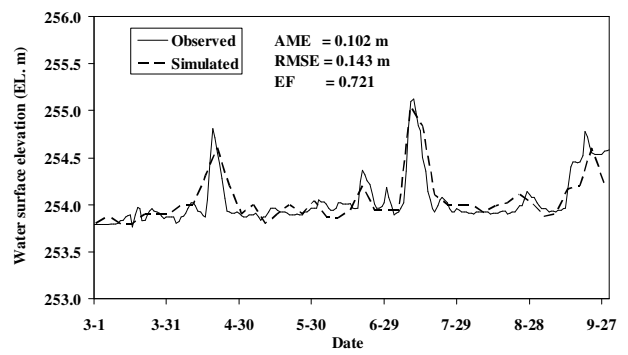

Fig. 4. Observed and simulated reservoir water surface elevations. 


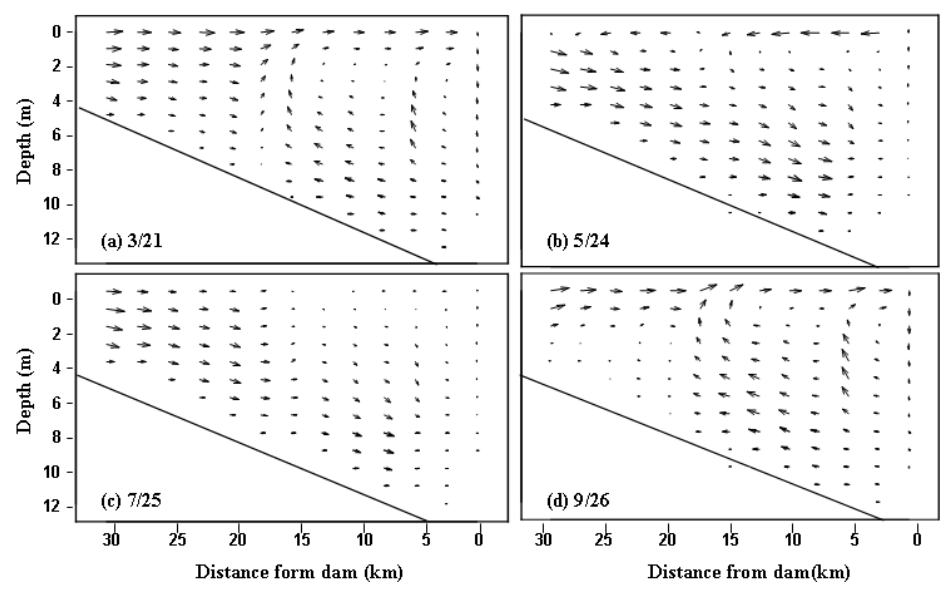

Fig. 5. Seasonal reservoir circulation patterns during (a) early spring, (b) late spring, (c) summer, and (d) fall.

Fig. 5 shows the computed flow velocity vectors on four different days from March to September. The velocity fields represent typical seasonal circulation patterns in the reservoir during early spring, late spring, summer, and fall, respectively. It should be noted that only part of the reservoir (about $30 \mathrm{~km}$ upstream from the dam) is plotted because of the large spatial variations in flow velocities between upstream and downstream. With a segment length of $2.5 \mathrm{~km}$ in the grid, the vector plots were not capable of capturing the insight into the velocity fields. However, the results are useful in examining the characteristics of large-scale seasonal water circulation patterns in the reservoir.

Two major circulation patterns were found during four different seasonal periods: overflow during early spring and fall and underflow during late spring and summer. During the early spring, inflows entered the reservoir as a plug flow at a distance of 20 $\mathrm{km}$ upstream from the dam, and moved toward the dam as forming an overflow because of the temperature difference between the upstream river waters and the reservoir water. The density of river water was slightly less than that of ambient reservoir water, resulting in an overflow. During fall, however, the river water was slightly colder than the ambient reservoir water, although the circulation pattern was similar to that in spring (Fig. 5). This implies that the dominant mixing mechanism during fall was convective overturn as surface waters cooled. The river water temperature during late spring and summer was about $1^{\circ} \mathrm{C}$ and $3^{\circ} \mathrm{C}$ less than that in reservoir surface, respectively. The negative buoyancy force induced by density differences resulted in the development of an underflow. The flow moved straight along the slope of the reservoir and formed an upward movement at the dam face. Strong winds during the late spring caused a reversal of flows near the surface of the reservoir. Weak reservoir mixing was expected near the dam and surface of the reservoir during the summer because of the formation of a plunge flow and an underflow (Fig. 5).

Reservoir stratification is a particular concern because it can result in water quality differences at various locations in the reservoir and reduce mixing between layers. Fig. 6 
depicts seasonal thermal structures of the reservoir using simulated water temperature contours at various times. Overall, the simulation results agreed well with the observed values, which were measured at surface, mid-depth, and bottom of the reservoir at about $0.3 \mathrm{~km}$ upstream from the dam. The water temperature was well-mixed in the vertical direction during the early spring (Fig. 6a). A weak longitudinal variation $\left(1.5^{\circ} \mathrm{C}\right)$ developed because of the temperature differences between river and reservoir waters. During late spring (Fig. 6b), a weak vertical stratification is noticed from the simulated results, while no stratification is observed from the field data. During summer (Fig. 6c), the longitudinal and vertical variations of water temperature were not significant (less than $4^{\circ} \mathrm{C}$ ). The errors between observed and simulated water temperatures near the dam were within $1{ }^{\circ} \mathrm{C}$. Slightly colder river water appeared in the upper part of the reservoir and pushed the warmer reservoir water, which was consistent with the unique circulation pattern described in the velocity vector plot (Fig. 5c). The thermal structure in the fall was characterized as a well-mixed condition in longitudinal and vertical directions as a result of convective overturn (Fig. 6d).

Temperature $\left({ }^{\circ} \mathrm{C}\right)$

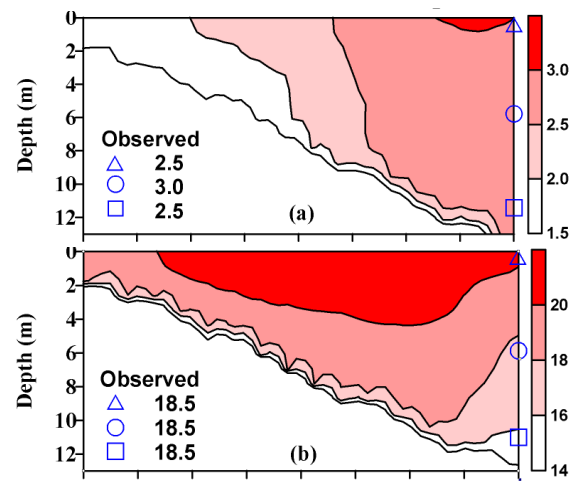

$\begin{array}{lllllllll}0 & 5 & 10 & 15 & 20 & 25 & 30 & 35 & 40\end{array}$ Distance from Inflow Boundary $(\mathbf{k m})$
Temperature $\left({ }^{\circ} \mathrm{C}\right)$

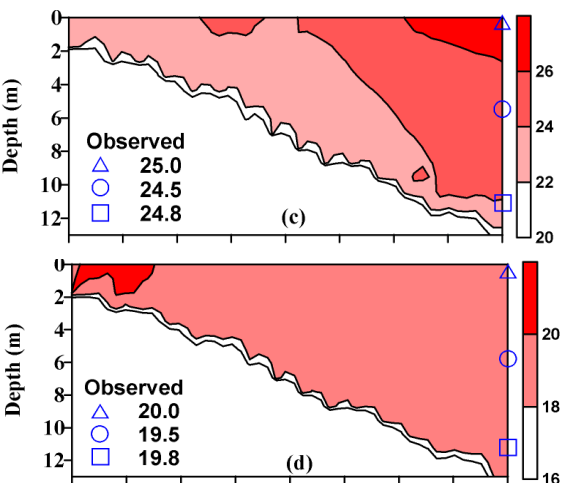

$\begin{array}{lllllllll}0 & 5 & 10 & 15 & 20 & 25 & 30 & 35 & 40\end{array}$ Distance from Inflow Boundary (km)

Fig. 6. Simulated and observed seasonal thermal structures of the Saylorville Reservoir during (a) early spring, (b) late spring, (c) summer, and (d) fall.

\subsection{Distribution of atrazine in the reservoir}

The contamination levels of atrazine in the reservoir for four different seasons are depicted by simulated concentrations in Fig. 7 together with observed concentrations at surface, middle, and bottom of the reservoir. Comparisons between the thermal structures and the spatial distributions of atrazine concentrations indicate a closerelationship between them. A weak chemical stratification appeared in late spring and summer, while well-mixed conditions observed during early spring and fall as noticed in the temperature contours. This is mainly attributed to the physical characteristics of atrazine, i.e., high solubility and low adsorption by suspended solids in water. 
As shown in Fig. 7a, the predicted atrazine concentrations in the reservoir during early spring were uniform in the range of 19-21 ng/L and compared well with the observed values at three depths. The well-mixed atrazine concentrations during that period are mainly the results of the steady state load of atrazine with low concentrations from upstream over the long winter period of the previous year. The atrazine concentrations in the upstream river waters (measured at Station 1) varied from 10 to 44 $\mathrm{ng} / \mathrm{L}$ during the winter period. A weak stratification formed in the late spring (Fig. 7b), which is consistent with the simulated thermal structure of the reservoir during the same period (Fig. 6b). Atrazine was distributed in the reservoir with concentrations of 800$1000 \mathrm{ng} / \mathrm{L}$ depending on the reservoir water depth. Predicted vertical distributions of atrazine near the dam agreed well with the observed values over the depths except at the bottom of the reservoir.

Atrazine (ng/L)
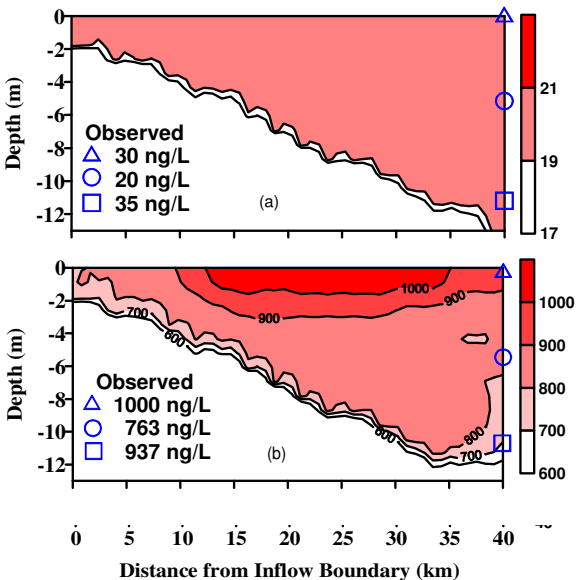

Atrazine (ng/L)
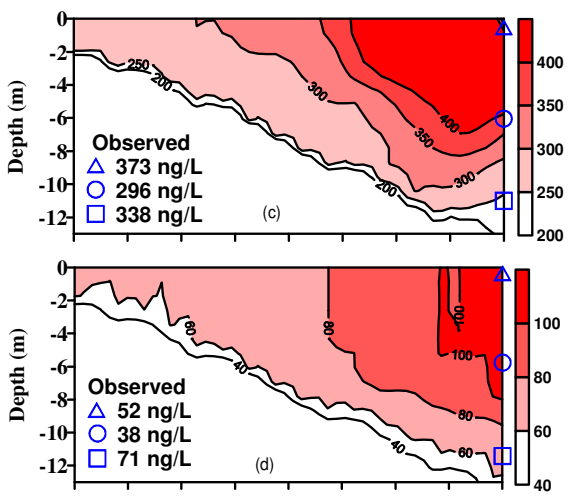

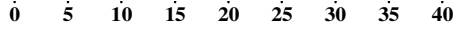
Distance from Inflow Boundary $(\mathrm{km})$

Fig. 7.Simulated and observed spatial distributions of atrazine in the Saylorville Reservoir during (a) early spring, (b) late spring, (c) summer, and (d) fall.

During summer, a relatively high level of atrazine appeared at the surface of the reservoir near the dam (Fig. 7c). This was expected from the insignificant mixing in the surface layers of reservoir as shown in the circulation pattern in Fig. 5c and was consistent with the thermal structure for that period (Fig. 6c). The successive inflows containing a low level of atrazine compare to the peak flows during spring intruded into the reservoir below the surface and flushed out the lower part of reservoir waters that contained elevated atrazine concentrations. The short-circuiting of flows led to less dilution and resulted in high atrazine concentrations near the surface of the reservoir. The distribution of atrazine during fall (Fig. 7d) is characterized as a well-mixed condition in the vertical direction with low concentrations less than $100 \mathrm{ng} / \mathrm{L}$. Significant vertical mixing induced by the convection processes (Fig. 5d) removed the weak stratification of atrazine that occurred during summer. Although the model overestimated concentrations 
near the surface, overall model performance in predicting the spatial distributions of atrazine in response to seasonal flow behavior is satisfactory.

\subsection{Temporal variations}

Temporal variations of water temperatures and atrazine concentrations at three depths (surface, middle, and bottom) in the reservoir were simulated and compared with observations. The model results were consistent with the variations of observed water temperatures and showed that no strong thermal stratification was present in both observed and simulated water temperatures. The simulated atrazine concentrations were in a reasonably good agreement with the measured values at all depths. The model successfully captured the peak concentrations occurred at the end of May and in early June.

The time series of averaged water temperatures and atrazine concentrations over the depth are presented in Fig. 8. The $\mathrm{r}^{2}$ value, which was used as an indicator for the performance of the model in predicting the temporal variations of observed temperatures and concentrations, was 0.97 and 0.84 for water temperature and atrazine concentrations, respectively. The $r^{2}$ values indicate that the model was reliable in generating the temporal variations of water temperatures and atrazine concentrations in the reservoir.
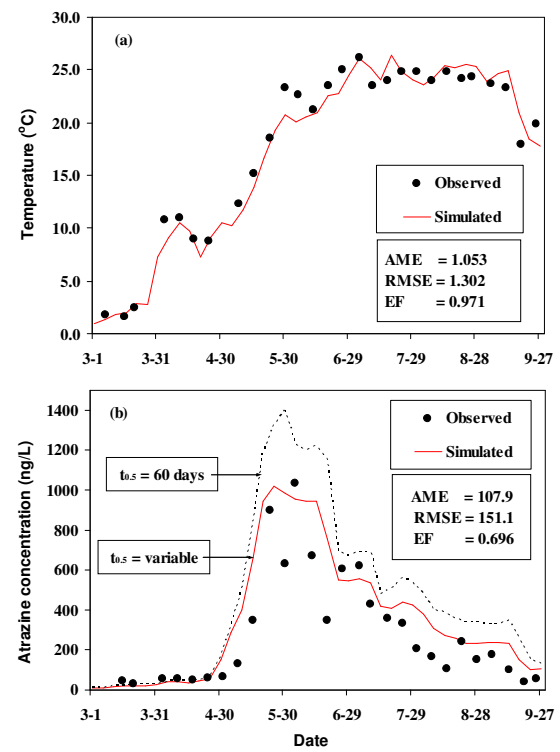

Fig. 8.Observed and simulated depth-mean (a) water temperatures and (b) atrazine concentrations versus time in the reservoir.

Model results obtained with a constant half-life value, 60 days that is generally known for atrazine half-life (Tomlin 1994), are also presented in Fig. 8b for comparison. The overestimation of atrazine concentration associated with the assumption of steady atrazine persistence (half-life 60 days) became significant after April and peaked at the time of maximum concentrations in early June. The simulated peak concentration was 
about $1400 \mathrm{ng} / \mathrm{L}$ at the end of May with the constant half-life, which is about $40 \%$ overestimation compared to the observed value and the simulated value with timevariable half-life $(1000 \mathrm{ng} / \mathrm{L})$. This implied that an accurate estimation of the kinetic transformation rate of atrazine for a specific aquatic environment should be made to obtain better model results.

\section{Conclusions}

The 2D reservoir toxiccontaminant model was successfully applied to Saylorville Reservoir, Iowa. The model was validated for the reservoir in predicting the fate and transport processes of atrazine in the reservoir. Measured water temperatures and atrazine concentrations were used to verify the simulation results, including seasonal flow circulation patterns, thermal structures, and spatial and temporal distributions of atrazine concentrations in the reservoir. Although a strong thermal stratification in the reservoir was not present in either the observed or simulated water temperatures, the spatial variation of atrazine concentrations was largely affected by hydrodynamic regimes and seasonal flow circulation patterns of the reservoir. In particular, the effect of flow shortcircuiting on the transport of atrazine was notable during summer months as the river inflow formed underflow within the reservoir and resulted in weak mixing and corresponding higher concentrations near the surface of the reservoir. The model simulated the temporal variations of observed atrazine concentrations reasonably well and verified the observed timing and magnitude of the peak concentrations that occurred at the end of May and in early June.

More accurate prediction of atrazine concentrations was obtained by using the sitespecific and time-variable kinetic transformation rates of atrazine. The assumption of steady or constant atrazine transformation rate over the entire period, i.e., under different environmental conditions, resulted in a $40 \%$ overestimation of peak atrazine concentrations. The results indicated that the persistence of atrazine in the reservoir was significantly affected by the environmental conditions such as temperature, sunlight, and microbial concentrations for different seasons. The results presented can provide a useful guide for reservoir water quality modeling and reservoir operation strategy development, e.g., timing, amount, and depth of discharges. Simulated spatial and temporal distributions of pesticides in a reservoir can be used for supporting decision making in selective withdrawal, raw water intake, spill control, and downstream water quality management.

\section{References}

1. J. Fallon, D. Tierney and E. Thurman, J. AWWA, 94, 54 (2002).

2. J. Hatfield, C. Wesley, J. Prueger and R. Pfeiffer, J. Environ. Qual. 25, 259 (1996).

3. D. Goolsby, E. Thurman, M. Pomes, and et al., Selected Papers on Agricultural Chemicals in Water Resources of the Midcontinental United States (U.S. Geological Survey, Denver, CO, 1993).

4. M. Patlak, Environ. Sci. Tech. 30, 210A (1996). 
5. G. Hallberg, Water quality and watersheds (Iowa State University Extension, Ames, IA, 1996).

6. T. Cole and E. Buchak, CE-QUAL-W2 (Army Corps of Engineers, Vicksburg, Miss., 1995).

7. J. Martin, J. Environ. Eng. 114, 317 (1988).

8. A. Bath and T. Timm, Commission Internationale Des Grands Barrages 69, 625 (1994).

9. R. Gu and S. Chung, J. Environ. Qual. 32, 620 (2003).

10. J. Schnoor, Environmental modeling (John Wiley \& Sons, Inc, New York, 1996).

11. E. Baumann, C. Beckert, M. Butler and D. Soballe, Water quality studies (Engineering Research Institute, Iowa State Univ., Ames, Iowa, 1979).

12. D. Lutz and A. Cavender, Water Quality Studies-Saylorville Reservoirs (Iowa State Univ., Ames, Iowa, 1997). 